\title{
ANATOMÍA de LA SEMILLA DE TIGRIDIA PAVONIA (IRIDACEAE)
}

\author{
Aída Carrillo-Ocampo y E. M. Engleman \\ Especialidad de Botánica, Colegio de Postgraduados, 56230 Montecillo, Estado de México, México. \\ Correo electrónico: aida@taurus1.chapingo.mx; marke@colpos.mx
}

\begin{abstract}
Resumen: Mediante microscopía de luz, tinciones histoquímicas y microscopía electrónica de barrido se determinó que el óvulo en la semilla de Tigridia pavonia (Iridaceae ) es anátropo, bitégmico y crasinucelar. Durante su desarrollo el exotegmen se aplasta y el endotegmen persiste con taninos en lúmenes y en paredes lignificadas. La exotesta tanificada tiene paredes externas convexas, engrosadas y cuticularizadas. La mesotesta pluriestratificada acumula lípidos abundantes y forma un abultamiento calazal. Las paredes de la endotesta se aplastan y tanifican. En la cálaza hay un cojín de hipostasa con taninos y paredes tanificadas y lignificadas. En el extremo micropilar existe un opérculo, constituido por: a) exotegmen poco aplastado, b) endotegmen con engrosamientos cuticulares concéntricos con respecto al micrópilo, c) depósitos hemisféricos de cutina en las paredes anticlinales del endotegmen, y d) una capa delgada de endospermo que cubre la radícula. El endospermo en etapa celular tiene paredes de transferencia conspicuas en el extremo calazal junto a la nucela. El embrión es pequeño y el cotiledón cónico.

Palabras clave: Tigridia, semilla, embriología, opérculo, Iridaceae

Abstract: With methods of light microscopy, histochemical staining and scanning electron microscopy, it was found that the ovule in the seed of Tigridia pavonia (Iridaceae) is anatropous, bitegmic, and crassinucellate. During development, the exotegmen is crushed and the endotegmen persists with tannins in the lumens and in the walls, which also react positively for lignin. The exotesta contains tannins and its outer walls are convex, thickened, and cuticularized. The mesotesta has multiple layers, accumulates abundant lipids, and forms a bulge in the chalaza. The cell walls of the endotesta collapse and accumulate tannins. In the chalaza, a hypostasal cushion contains tannins in the lumens and in the walls, which also react positively for lignin. At the micropylar end of the seed there is an operculum which consists of: a) a slightly crushed exotegmen, b) an endotegmen with cuticular thickenings that are concentric with respect to the micropyle, c) hemispherical deposists of cutin on the anticlinal walls of the endotegmen, and c) a thin layer of endosperm that covers the radicle. During its cellular stage of development, the endosperm has conspicuous transfer walls at the chalazal end next to the nucella. The embryo is small and has a conical cotyledon.
\end{abstract}

Key words: Tigridia, seed, embryology, operculum, Iridaceae

$\mathbf{E}$ n México el oceloxóchitl, Tigridia pavonia (L. f.) DC., fue utilizada por los aztecas (Molseed, 1970) como ornamental, alimenticia y medicinal (Martínez, 1967), pero actualmente es una planta poco apreciada y conocida. Para Molseed (1970) es imposible delimitar con exactitud la distribución natural de $T$. pavonia, ya que el hombre ha contribuido notablemente a su abundancia y amplia distribución desde tiempos prehispánicos. En México $T$. pavonia se localiza en una gran diversidad de ambientes, excepto el alpino y el árido, principalmente como "semisilvestre", "escapada" o cultivada (Molseed, 1970). En cuanto a la familia Iridaceae, Huber (1969, Mitteilungen der Botanischen Staatssammlung München 8: 219-538; citado por Goldblatt,1990) encontró caracteres morfológicos en las semillas que permiten formar grupos de géneros.
Netolitzky (1926) consignó características anatómicas de las semillas de algunas especies de Iris, Moraea, Sisyrinchium, Gladiolus, Romulea y Crocus, encontradas por él y otros autores, acerca de la cubierta seminal, la zona calazal y el endospermo. En la literatura (Lenz, 1956; Rudall et al., 1984; Chichiricó, 1989; Manning y Goldblatt, 1991) se encuentra la embriología de Iris, Crocus y varias Nivenoideae leñosas. Para Danilova et al. (1995), el origen y las características estructurales de la cubierta seminal pueden permitir establecer relaciones entre familias de monocotiledóneas; además, la estructura de las zonas calazal y micropilar y la ornamentación de la cubierta son valiosas para definir subfamilias. Hasta donde sabemos, no existe información acerca de la estructura de la semilla del género Tigridia, por lo que aquí se informan, para una especie, los 
cambios en su anatomía desde la antesis hasta semilla madura, con el fin de aportar conocimiento básico.

\section{Materiales y métodos.}

En un predio ubicado en San Miguel Tlaixpan, Texcoco, Edo. de México, se marcaron diariamente durante agosto y septiembre de 1997 y 1998 plantas cultivadas de Tigridia pavonia que presentaban la primera flor en antesis de la inflorescencia. El reconocimiento de esta primera flor se facilita ya que las flores abren por la mañana y al atardecer el perigonio está delicuescente. Se recolectaron flores y frutos en diferentes etapas de desarrollo diariamente desde un día antes de la antesis hasta 8 días posteriores a la misma, y cada 5-7 días hasta la dehiscencia del fruto. El material recolectado se fijó en Craf III y en FAA (Sass, 1958). Después de $24 \mathrm{~h}$ se lavó con agua corriente y se conservó en GAA (glicerol al $25 \%$ v/v, alcohol al $50 \%$ v/v y agua al $25 \% \mathrm{v} / \mathrm{v}$ ). Las muestras se procesaron de acuerdo a la técnica usual de la parafina (Sass, 1958) y se hicieron cortes seriados longitudinales y transversales a 8-10 $\mu \mathrm{m}$ de grosor. Se utilizó la tinción general safranina 0 -verde fijo FCF, la cual tiñe las paredes celulósicas de azul verde, las paredes lignificadas y los núcleos de rojo, y el citoplasma de morado o verdeazul. Algunos cortes se tiñeron con rojo $\mathrm{O}$ de aceite que destaca la presencia de lípidos y cutículas; con ácido peryódico-reactivo de Schiff (APS) que tiñe polisacáridos de color rosa, y con azul negro de naftol, un colorante con afinidad para proteínas (Fisher, 1968). En cortes a mano de semillas (tejido fresco o conservado en GAA) en diferentes etapas de desarrollo se probó la presencia de taninos (catequinas y leucoantocianidinas), a través de la prueba de vainillina-ácido clorhídrico (Gardner, 1975). Para lípidos se empleó rojo $\mathrm{O}$ de aceite y para almidón se usó Lugol (solución saturada de yodo en $0.5 \%$ de yoduro de potasio). La lignina se destacó con: $2 \%$ floroglucinol en etanol $+\mathrm{HCl}$ concentrado (modificada de Johansen, 1940).

En el laboratorio de Microscopía Electrónica del Colegio de Postgraduados se procesaron óvulos, semillas jóvenes y semillas maduras para su estudio con microscopía de barrido. Las muestras se deshidrataron hasta alcohol absoluto y se secaron por punto crítico. Se montaron sobre portaobjetos cilíndricos de metal, se recubrieron con $\approx 7 \mathrm{~nm}$ de oro en una ionizadora a 1200 voltios, y se registraron fotográficamente con película Verichrome Pan formato 120.

\section{Resultados}

Tigridia pavonia posee flores fugaces que permanecen abiertas alrededor de 12 horas y cierran en forma delicuescente. El ovario es ínfero, tricarpelar y trilocular, y en cada lóculo hay dos hileras de óvulos subsésiles con papilas en su base (figura 1) y placentación axial. La llegada del tubo polínico puede ocurrir desde el primer día de la antesis.
Los óvulos son anátropos, bitégmicos (figura 1) y crasinucelares.

El tegumento externo. En los primeros días después de la antesis (dda) la testa está formada por exotesta, mesotesta y endotesta (figura 4) con abundantes granos de almidón que se concentran hacia la zona del micrópilo. La exotesta y la endotesta son uniestratificadas (figura 4), aunque a los nueve días dda la endotesta forma dos estratos en algunas zonas de la semilla. Inicialmente sólo hay pocas células de la exotesta con taninos condensados. En la semilla madura todas las células de la exotesta contienen taninos compactos; sus paredes periclinales externas son convexas y más gruesas que las periclinales internas, y las externas están cubiertas por una cutícula finamente ondulada (figuras 6 y 7). Adentro de la cutícula una franja delgada de la pared celulósica se tiñe de rojo con floroglucinol y $\mathrm{HCl}$ concentrado. $\mathrm{La}$ mesotesta, de un solo estrato en la antesis, por divisiones periclinales aumenta a la madurez hasta cinco estratos (figuras 6 y 7) o aun 11 estratos; en la rafe presenta hasta 15 estratos, lo que hace que se vea abultada. A los 10-11 días dda, las células de la mesotesta contienen abundantes granos de almidón; las más cercanas a la cálaza también contienen lípidos; la mesotesta de la región hilo-micropilar tiene espacios intercelulares notorios. A los 57-71 dda todas las células de la mesotesta contienen menos almidón y más lípidos y taninos. A los 78 dda en la semilla completamente madura, las células se colapsan y quedan con lípidos abundantes y algo de taninos. Sólo persisten los granos de almidón en la mesotesta de la cálaza. En esta etapa, todas las paredes de todos los estratos de la testa están conspicuamente engrosadas y aplastadas periclinalmente. Hay taninos condensados en lúmenes y paredes (figura 7).

El tegumento interno. En el óvulo y la semilla muy joven a los 1-2 dda, el tegmen sobresale de la testa y forma el endóstomo (figura 1). Está constituido por exotegmen con abundantes granos de almidón y endotegmen con taninos más abundantes hacia el polo micropilar; ambos estratos están conformados por células isodiamétricas. El exotegmen forma dos y luego 3-5 estratos de células (figura 4) con almidón. Entre el exotegmen y la endotesta hay una cutícula intertegumentaria notoria. A los 9-11 dda los dos estratos más externos del exotegmen aumentan su volumen en una zona a $70 \%$ de distancia a partir del micrópilo hacia la cálaza, lo que ocasiona que el saco embrionario se haga piriforme (figura 2). A los 13-21 dda el volumen de estas células aumenta más (figura 5). Las células del exotegmen contienen almidón y a los 36-43 dda, cuando el endospermo ya es completamente celular, se inicia el colapso del exotegmen (figuras 3 y 6 ). Hacia el polo calazal se conservan 2-4 estratos de exotegmen con almidón y en el endóstomo persisten 1-2 estratos de células alargadas en sentido paralelo al eje del micrópilo. En la semilla completamente madura 


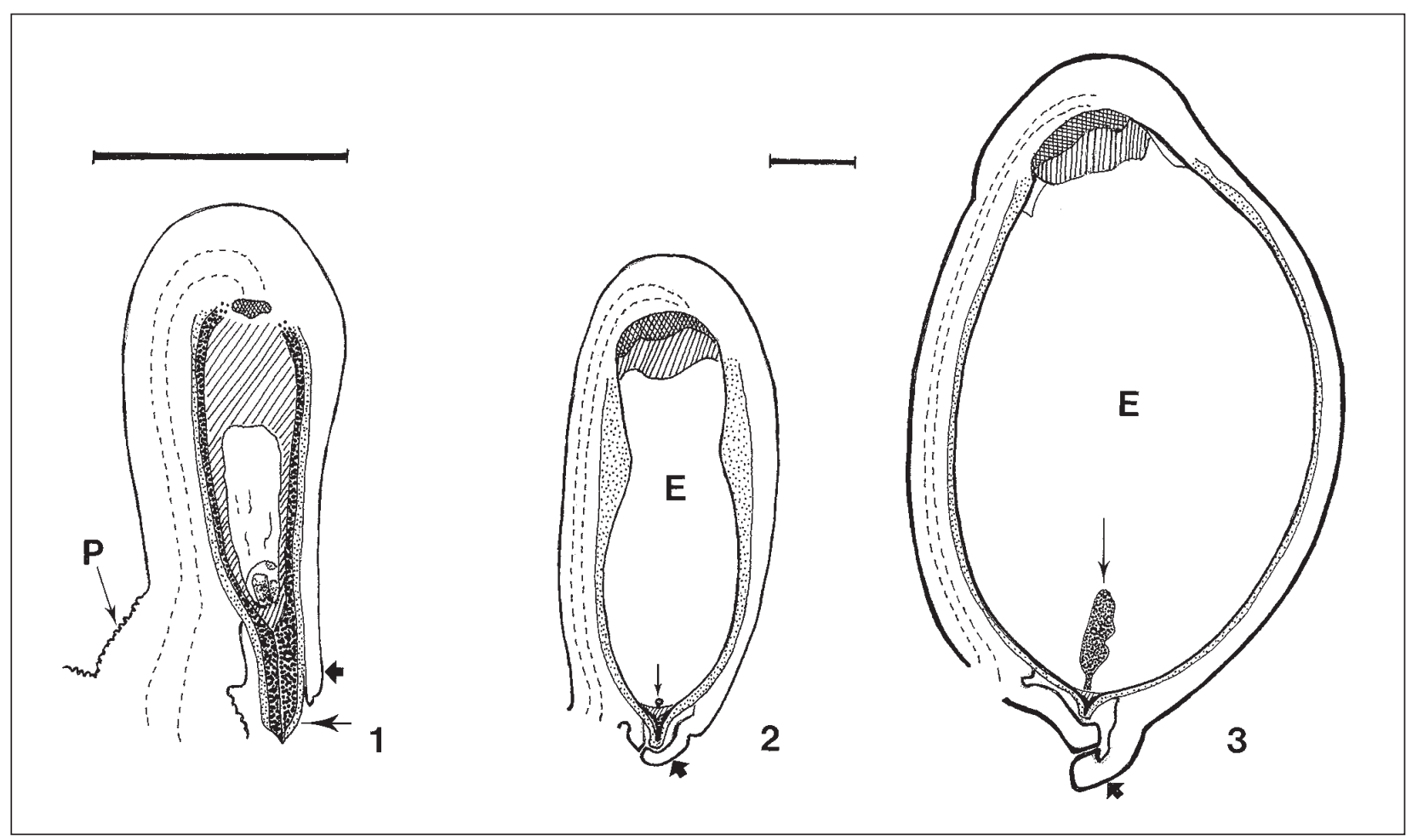

Figuras 1-3. Cambios en la forma del saco embrionario, la región micropiliar y el embrión. 1) A los 0-3 dda el saco embrionario es muy alargado; la gorra de la nucela está dentro del endóstomo (flecha delgada) que crece más que el exóstomo (flecha gruesa). 2) A los 1321 dda el saco embrionario es piriforme, el embrión esférico es muy pequeño (flecha delgada) y el exóstomo (flecha gruesa) rodea el endóstomo. 3) A los 36-43 dda el embrión (flecha delgada) es cilíndrico, ocupa el 1\% o menos del volumen total de la semilla y está rodeado por el endospermo. Cuadros= hipostasa; $\mathrm{dda}=$ días después de la antesis; $\mathrm{E}=$ endospermo; líneas inclinadas= nucela; línea interrumpida $=$ tejido vascular de la rafe; $\mathrm{P}=$ papilas del obturador; zona punteada clara= exotegmen; zona punteada oscura= endotegmen. Escala: 1,2 y $3=500 \mu \mathrm{m}$.

el exotegmen queda reducido a una capa de paredes muy aplastadas (figuras 6 y 7 ).

En la mayor parte de la semilla las células del endotegmen, inicialmente isodiamétricas, crecen en forma tabular y su lumen es ocupado por taninos persistentes y uniformes (figuras 6 y 7); sus paredes anticlinales se ondulan y son más delgadas en su parte central. Finalmente todas las paredes del endotegmen se engruesan, tanifican y lignifican. Este estrato se aplasta pero se conserva hasta la madurez total de la semilla (figura 7). Las células del endotegmen junto al gorro de la nucela quedan isodiamétricas o alargadas en sentido oblicuo a la cutícula (figura 12). Las que rodean el canal del endóstomo se alargan en sentido paralelo al eje del mismo. Estas células tienen las paredes y lúmenes con abundantes taninos condensados de diversas formas, tamaños y colores.
La hipostasa y la zona calazal. Desde el primer día de la antesis en la base de la nucela hay dos estratos con 3-4 células de ancho con taninos adosados a las paredes, que representan el inicio de la hipostasa (figura 1) y casi llenan el orificio calazal del tegumento interno. Posteriormente, conforme la semilla crece y se desarrolla, el número de células de la hipostasa aumenta, hasta formar un cojín de varios estratos de células con taninos conspicuos (figura 8). En la semilla madura, las células de la hipostasa se colapsan ligeramente (figura 9), sus lúmenes se llenan con taninos castaños y sus paredes también se tanifican, lo que fue confirmado a través de las pruebas (con vainillina- $\mathrm{HCl}$ concentrado) y lignifican (floroglucinol-HCl concentrado). La epidermis externa (exotesta) de la cálaza comparte las mismas características estructurales y de desarrollo que el resto de la exotesta. Por debajo de la exotesta hay 1-2 estratos de células de la 


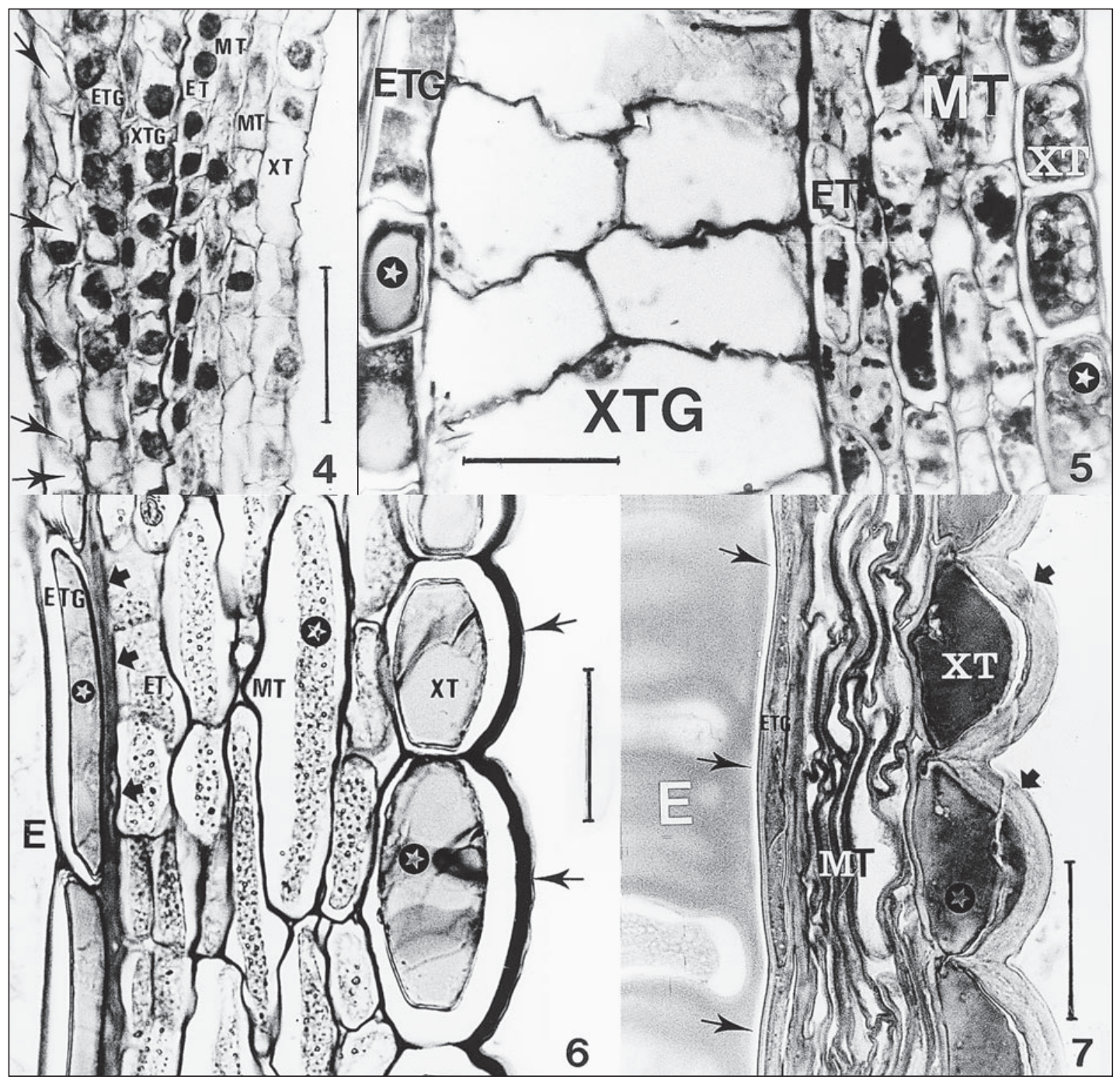

Figuras 4-7. Secciones longitudinales. Parte media de la cubierta seminal de T. pavonia en diferentes etapas de desarrollo. 4) A los 0-3 dda quedan 1-2 estratos de la nucela (flechas). La cubierta seminal está constituida por el endotegmen, el exotegmen, la endotesta, la mesotesta de dos estratos y la exotesta. 5) A los 13-14 dda las células del exotegmen aumentan notablemente su volumen, especialmente aquí donde se constriñe el saco embrionario (ver figura 2). El endotegmen y la exotesta acumulan más taninos (asteriscos). 6) A los 36-43 dda el exotegmen está totalmente aplastado (flechas gruesas). Las células de todos los estratos se agrandan y alargan en sentido longitudinal y su lumen está ocupado por taninos (asteriscos). La pared periclinal externa de la exotesta es convexa y tanificada (flechas delgadas). 7) A los 78 dda las células de todos los estratos se han aplastado. Sus lúmenes y paredes están impregnados con taninos. La pared periclinal externa de la exotesta es más gruesa (flechas gruesas) y la cutícula nucelar es muy notoria (flechas delgadas). dda= días después de la antesis; E= endospermo; ET= endotesta; ETG= endotegmen; MT= mesotesta; XT= exotesta; $\mathrm{XTG}=$ exotegmen. Escala $40 \mu \mathrm{m}$. 
mesotesta (figura 8) con cloroplastos que luego producen granos de almidón grandes y abundantes; enseguida hay células muy grandes ligeramente extendidas periclinalmente y con paredes celulares y envoltura nuclear onduladas que forman un abultamiento calazal en el extremo proximal de la semilla (figura 8). El citoplasma de estas células es muy denso y de apariencia fibrilar; inicialmente se tiñe con azul-negro de naftol, a los 11 dda presenta reacción positiva a lípidos (rojo $\mathrm{O}$ de aceite en cortes no procesados) y contiene pequeños granos de almidón (detectados a través de APS). A los 14 dda en estas mismas células son visibles unos corpúsculos elipsoidales cuyo diámetro mayor mide de 5-15 $\mu \mathrm{m}$, los cuales tiñen con azul negro de naftol. Estos corpúsculos aumentan de tamaño conforme aumenta el tamaño de las células que los contienen. A medida que la semilla se desarrolla desaparecen los granos de almidón de las células del abultamiento calazal, aumentan los taninos y los lípidos, el citoplasma se mantiene y sus paredes se engruesan y tanifican. Dos meses y medio después de la antesis todos los tejidos de la cálaza están colapsados en diferentes sentidos y sus paredes están engrosadas y tanificadas (figura 9). Sin ninguna tinción los lípidos contenidos en las células del abultamiento calazal son de color amarillo intenso, son pegajosos, y se estiran formando hilos. Un haz anficribal penetra por el funículo y recorre la rafe (figuras 8 y 9). El xilema desemboca en la parte media de la hipostasa por encima del xilema, el floema se proyecta más allá en forma de abanico y llega casi a tocar el extremo proximal del endotegmen. Las células del parénquima vascular son pequeñas, con citoplasma denso y núcleo grande.

El micrópilo. En el óvulo y la semilla muy joven, el tegmen sobresale de la testa y forma el endóstomo cuyo extremo distal queda muy cerca de las papilas del funículo y de la placenta (figura 1). El tubo polínico penetra por el endóstomo y llega hasta las células del gorro de la nucela. A medida que la semilla se desarrolla, 11 dda, el exóstomo crece sobre el endóstomo, y lo cubre completamente (figura 2); este cambio coincide con la presencia del cigoto, el aumento en volumen de dos estratos del exotegmen, y el depósito de lípidos en las células parenquimáticas del abultamiento calazal. En esta etapa las células del exóstomo concentran la mayor cantidad de almidón. En la semilla joven el endóstomo está conformado por endotegmen y exotegmen masivos desarrollados por medio de divisiones periclinales. En la madurez de la semilla el canal del endóstomo está rodeado por exotegmen de dos estratos y endotegmen de 2-3 estratos de células muy grandes con paredes gruesas tanificadas y lúmenes con taninos muy obscuros. Entre el extremo más distal del endóstomo y el extremo proximal del exóstomo queda un espacio de aire (figura 3). El tubo polínico persiste en el endóstomo y exóstomo en la madurez de la semilla. Las células del endotegmen que cubren la gorra de la nucela y el canal del endóstomo tienen engrosamientos cuticulares concéntricos con respecto al micrópilo y cuerpos hemisféricos de cutina en sus paredes anticlinales (figuras 11, 12 y 13). En la semilla madura, el endóstomo es más rígido que el exóstomo, posiblemente debido a que los engrosamientos cuticulares y los depósitos de cutina del endotegmen se hacen más espesos conforme la semilla madura.

El opérculo. En el extremo distal de la semilla hay un opérculo con forma de embudo cuyo diámetro basal mide de 400-600 $\mu \mathrm{m}$ (figura 10). En el inicio de la germinación, el opérculo se levanta como una tapa intacta, pero sin romper la testa. Los tejidos que forman parte del opérculo son exotegmen, endotegmen y las células del endospermo que cubren la radícula. Estas células tienen paredes delgadas impregnadas con taninos, y citoplasma con granos de almidón grandes y abundantes. Cuando la radícula crece más, rompe la testa irregularmente y el opérculo se hace visible.

Desde antes de la antesis, en el polo micropilar el opérculo se distingue porque las células del exotegmen y endotegmen son más grandes. En cortes longitudinales de óvulos, no procesados y teñidos para lípidos (rojo $\mathrm{O}$ de aceite), la cutícula nucelar forma engrosamientos en forma de cuñas, que se introducen entre las paredes anticlinales del endotegmen del opérculo (los cuales corresponden a los engrosamientos concéntricos de la cutícula nucelar del opérculo, que se observan en la figura 11). A los 21-25 dda en cortes longitudinales, es posible distinguir en el ápice de las cuñas de cutícula, un par de estructuras hemisféricas sobre las paredes anticlinales del endotegmen, que también se tiñen con rojo $\mathrm{O}$ de aceite. Nosotros interpretamos estas estructuras hemisféricas como depósitos muy espesos de cutina con base en pruebas de solubilidad. Diferentes opérculos con estos engrosamientos se colocaron durante un mes y por separado, en tolueno, xileno, benceno, dimetilsulfóxido, cloroformo y éter, no se encontró ningún cambio aparente en estos cuerpos hemisféricos, al observarlos al microscopio de disección y óptico. A los 28 dda los depósitos de cutina tienen una superficie muy irregular y son más notorios en la región del opérculo. En la semilla madura tanto los engrosamientos concéntricos como los cuerpos de cutina aumentan de grosor y éstos últimos invaden el lumen de las células del endotegmen y reducen parcialmente el espacio ocupado por taninos (figuras 11 y 12). En cortes longitudinales procesados a partir de semilla madura, se encontró que, además de la cutícula nucelar, las paredes del endospermo también penetran entre la lámina media de las paredes anticlinales de algunas células del endotegmen del opérculo (figura 12).

Al realizar diversas pruebas histoquímicas, que a continuación se explican, se determinó que los depósitos hemisféricos de cutina cambian su composición química, que es compleja, durante el desarrollo de la semilla. A los 25-36 dda la periferia de los cuerpos de cutina, se tiñe de verde con safranina-verde rápido, lo mismo que el resto de las paredes del endotegmen. A los 78 dda se encontró que alrededor del 

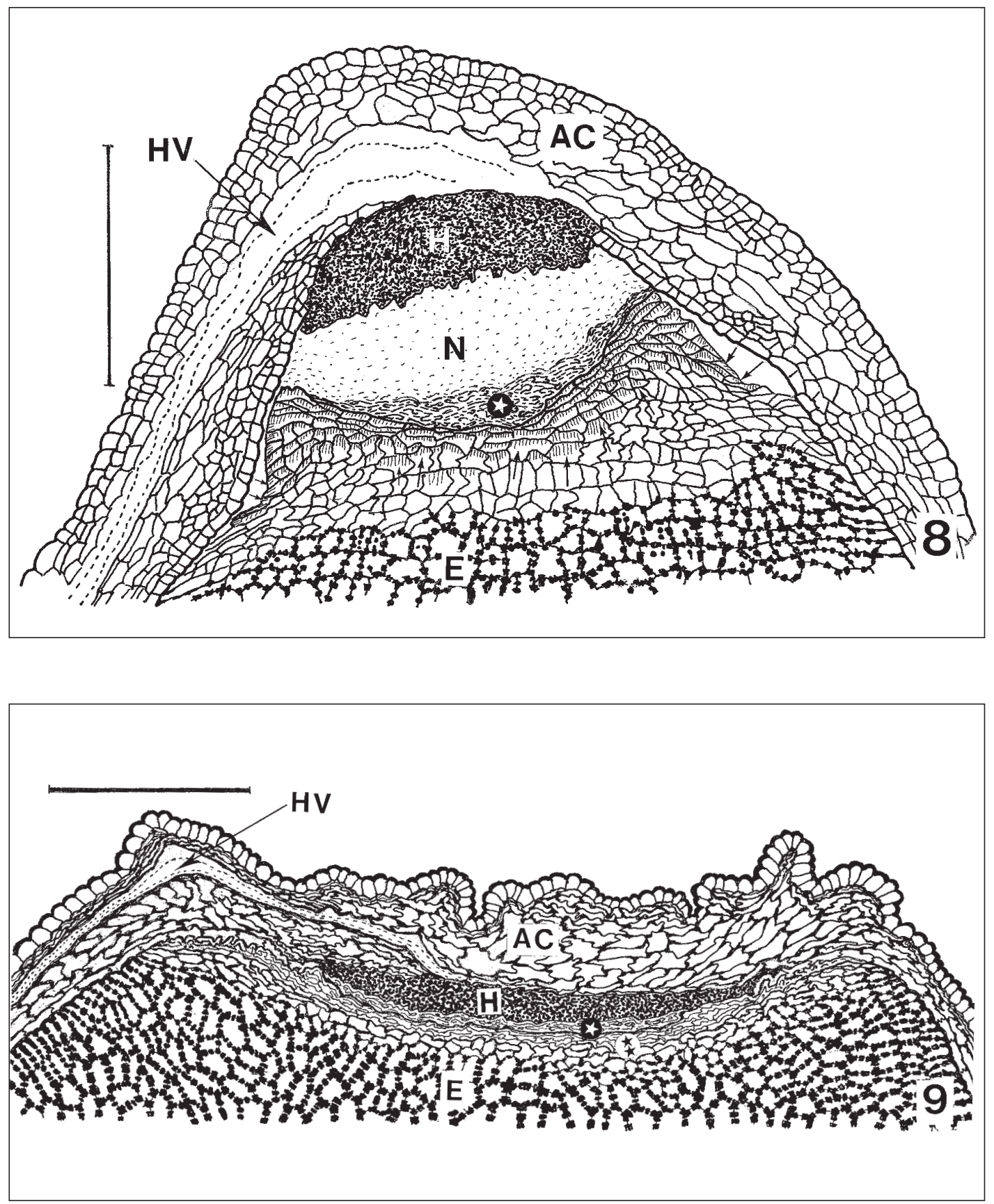

Figuras 8-9. Dos etapas del desarrollo de la zona calazal. 8) A los 36-43 dda el abultamiento calazal es conspicuo y está constituido principalmente por las células de la mesotesta, a través de las cuales corre un haz vascular. La hipostasa y la nucela calazal son notorias en esta etapa. Hay paredes de transferencia (flechas) en el endospermo, en la zona de contacto con la nucela colapsada (asterisco blanco). 9) A los 78 dda el abultamiento calazal se aplasta en diferentes sentidos; la hipostasa y la nucela calazal (asterisco blanco) están muy colapsadas; las paredes del endospermo son más engrosadas que en la etapa anterior. Una franja tortuosa que tiñe con safranina, marca el contacto entre restos de nucela (asterisco blanco) y endospermo colapsado (asterisco doble). $\mathrm{AC}=$ abultamiento calazal; $\mathrm{E}=$ endospermo; $\mathrm{H}=$ hipostasa; $\mathrm{HV}=$ haz vascular; $\mathrm{N}=$ nucela calazal. Escala $=500 \mu \mathrm{m}$. 


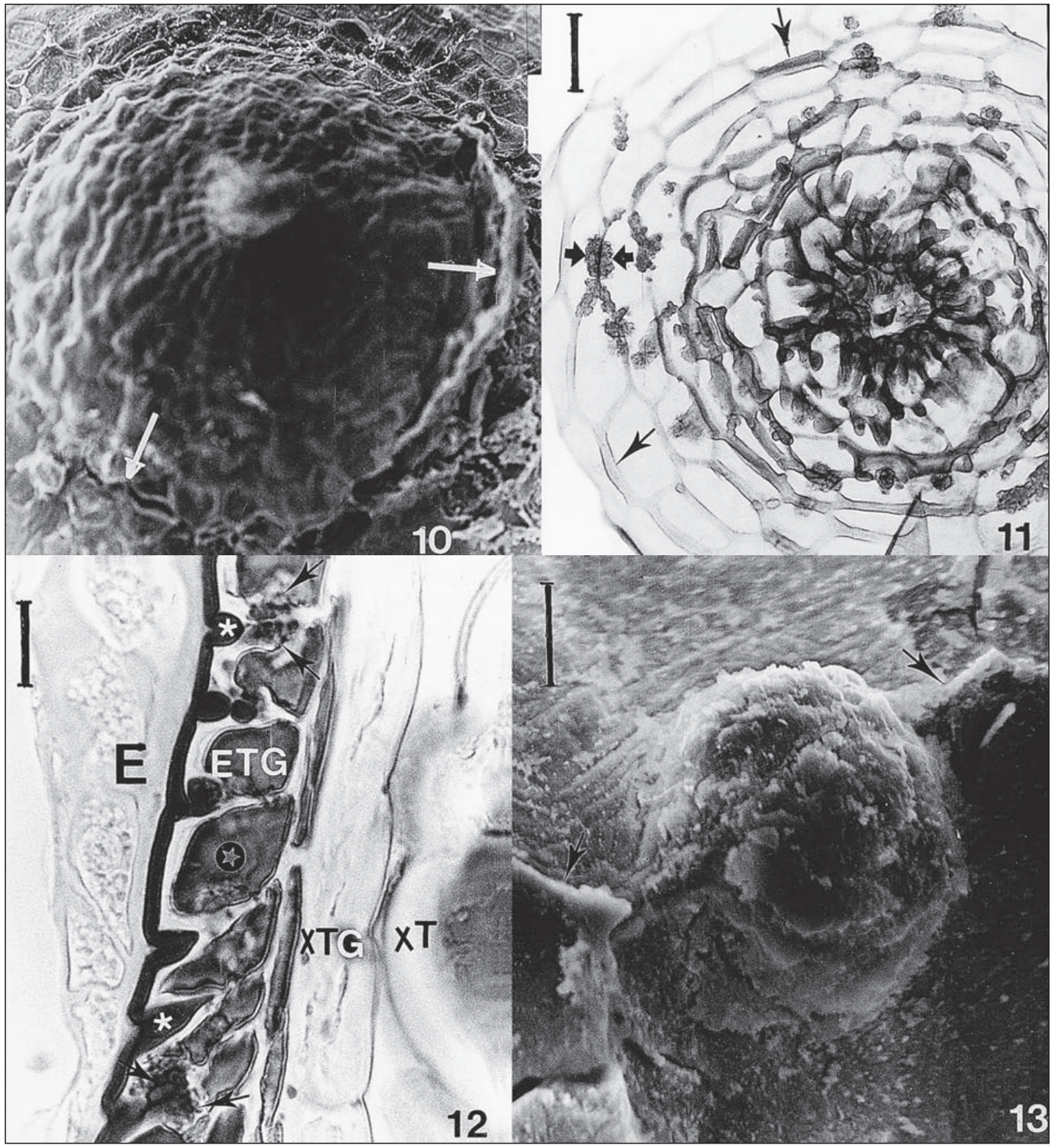

Figuras 10-13. Detalles del opérculo de la semilla de T. pavonia. 10) Vista frontal del opérculo completo visto con MEB; las flechas señalan la línea de dehiscencia. 11) Vista frontal de la cutícula que recubre el lado interno del opérculo (obtenida a partir de semilla germinada y teñida para lípidos, vista con MO). Presenta engrosamientos concéntricos (flechas delgadas) con respecto al micrópilo y cuerpos de cutina (flechas gruesas). 12) Corte longitudinal de la semilla, teñida para lípidos, mostrando cómo la cutícula nucelar forma cuñas entre las paredes anticlinales del endotegmen (asteriscos blancos); los cuerpos de cutina (flechas) invaden el lumen de estas mismas células. Los taninos del lumen son castaños (asterisco). 13) Depósito de cutina sobre las paredes anticlinales (flechas), del endotegmen del opérculo visto con $\mathrm{MEB}$. $\mathrm{E}=$ endospermo; $\mathrm{ETG}=$ endotegmen; $\mathrm{MEB}=$ microscopio electrónico de barrido; $\mathrm{MO}=$ microscopio óptico; $\mathrm{XT}=$ exotesta; $X T G=$ exotegmen. Escala: 10,11 y $12=100 \mu \mathrm{m} ; 13=10 \mu \mathrm{m}$. 
corazón lipídico del espesamiento de cutina, que se tiñe de rojo con rojo $\mathrm{O}$ de aceite, algunas zonas se tiñen de rosa, con APS (carbohidratos), mientras que otras se tiñen de azul, con azul-negro de naftol. Con vainillina-HCl (taninos condensados), los cuerpos de cutina se tiñen de rojo, al igual que las paredes del endotegmen. En preparaciones de cutícula nucelar del opérculo, aislada por disociación y teñida con rojo $\mathrm{O}$ de aceite (obtenidas a partir de semillas germinadas, en las que el cotiledón ya había consumido casi todo el endospermo), se encontró que los cuerpos de cutina están conformados por un conjunto de pequeñas gotitas lipídicas que permanecen adheridas a los engrosamientos concéntricos (figura 11) de la cutícula nucelar, por lo que aparentemente forman parte de ella. Al revisar con microscopio estereoscópico semillas maduras, a las cuales se les retiró la testa, los depósitos de cutina semejan pequeñas verrugas, con el centro claro y la periferia de color castaño obscuro, y son particularmente abundantes en las paredes anticlinales del endotegmen paralelas a la periferia del opérculo. Al microscopio electrónico de barrido (MEB), en muestras de semillas maduras a las que se les retiró el exotegmen y la pared periclinal externa del endotegmen, estos cuerpos de cutina tienen formas globulares o cilíndricas y su superficie es porosa e irregular (figuras 11 y 13). En el endotegmen visto al MEB se distingue claramente la línea de dehiscencia del opérculo (figura 10).

La nucela, el endospermo y el embrión. A los 1-3 dda hacia el polo calazal hay una nucela masiva (figura 1) resultado de muchas divisiones en diferentes planos; sus células tienen núcleos conspicuos y citoplasma denso, con granos de almidón pequeños y escasos. Hacia el polo micropilar existe una gorra de la nucela (figura 1) formada por 2-3 estratos de células alargadas con vacuola grande; antes de los 43 dda estas células se colapsan. En el resto del óvulo, hay 1-2 estratos de nucela alrededor de las paredes laterales del saco embrionario, las cuales se colapsan a los 5-7 dda. El endospermo cenocítico avanza en torno de la nucela calazal proliferante y se deshacen las células más cercanas a él, lo que ocasiona que inicialmente la nucela adopte la forma de un cono obtuso con el vértice dirigido hacia el micrópilo. Las células de la nucela más cercanas a la cálaza son pequeñas y se tiñen intensamente con azul negro de naftol; las que están en contacto con el endospermo nuclear se ven vacías y con paredes colapsadas que se tiñen fuertemente con APS, algunas tienen sus protoplastos contraídos. A medida que la semilla se desarrolla, el endospermo invade gradualmente el espacio ocupado por la nucela del polo calazal (figuras 2 y 3). En la semilla totalmente madura a los 78 dda, la nucela ya es solamente una masa aplastada y compacta de paredes celulares teñidas intensamente con APS o de verde con safranina-verde fijo (figura 9). La cutícula nucelar es ondulada y su grosor aumenta conforme la semilla crece y madura (figura 7). En la cálaza donde la cutícula se interrumpe, entre las células de la nucela y de la hipostasa, hay 2-3 estratos de células rodeadas por una capa muy delgada con reacción positiva a rojo $\mathrm{O}$ de aceite para detectar lípidos (supuestamente cutícula; son cortes previamente expuestos al alcohol y xileno).

Desde 1-2 dda puede haber abundantes núcleos libres del endospermo adosados a la pared del saco embrionario, el cual presenta paredes de transferencia. A los 25-28 dda el endospermo forma paredes delgadas en sentido centrípeto; sus células tienen 1-2 núcleos notorios con varios nucléolos, vacuola grande, citoplasma denso y granos de almidón muy pequeños y escasos; hacia los extremos calazal y micropilar ocurren muchas mitosis y las hileras de células son más largas que en el ecuador. El endospermo celular en contacto con la nucela calazal desarrolla paredes de trasferencia conspicuas (figura 8), sus células son más grandes, sus paredes se quedan mucho más delgadas que las del resto del endospermo y tienen una vacuola muy grande; aparentemente no acumulan reservas y así permanecen hasta la madurez total de la semilla. A los 36-43 dda termina la celularización del endospermo. Sus paredes comienzan a engrosar a partir de la zona central de la semilla y hacia la cálaza. En esta etapa el citoplasma de las células isodiamétricas del endospermo se tiñe ligeramente con rojo $\mathrm{O}$ de aceite en cortes no procesados, también contiene granos de almidón pequeños y muy escasos. A los 38-45 dda, las paredes de las células del centro del endospermo están más engrosadas, contienen un núcleo pequeño con 2-5 nucléolos, y son las que almacenan mayor abundancia de glóbulos de proteínas, lípidos y granos de almidón grandes. Las paredes de las células del endospermo que rodean el embrión son más delgadas. A los 50-64 dda las paredes de la mayoría de las células del endospermo han alcanzado su grosor final y forman hileras radiales dirigidas hacia el centro del endospermo, en donde se ubican células sin un arreglo aparente; la cantidad de reservas que almacenan es semejante, tienen núcleo poco notorio y punteaduras conspicuas, excepto las que limitan con la pared del saco embrionario y las de la zona con paredes de transferencia; éstas últimas comienzan a colapsarse a los 57-71 dda. A los 78 dda, las paredes de las células del endospermo cercanas a las células de la nucela son un poco más engrosadas que en etapas anteriores, pero siguen siendo más delgadas que las del resto del endospermo (figura 9) se tiñen con APS o verde fijo al igual que la madeja de células colapsadas de la nucela. En el límite de la nucela aplastada y el endospermo, hay una línea tortuosa de paredes aplastadas (figura 9), que se tiñe de rojo con safranina-verde fijo y que presenta reacción positiva a grasas y taninos. Las paredes engrosadas de las células del endospermo muestran tres estratos: a) el que está junto a la lámina media y se tiñe con APS, b) el intermedio que se tiñe con azul negro de naftol, y c) la parte más interna adyacente a la plasmalema que no se tiñe. Las células del endospermo en contacto con las paredes laterales del saco embrionario se tiñen muy fuertemente con azul negro de naftol. Todas las células del 
endospermo tienen taninos escasos, abundantes glóbulos de grasa y proteínas de diversos tamaños. El endospermo que rodea el embrión contiene granos de almidón pequeños (detectados a partir de la prueba con Lugol), los cuales son particularmente abundantes hacia la radícula.

A los 13-14 dda el cigoto, que contiene abundantes y conspicuos granos de almidón alrededor de un núcleo notorio, presenta divisiones transversales. A los 21 dda en el embrión globular (figura 2) hay granos de almidón y paredes de transferencia notorias en las células de la base del suspensor y en la pared del saco embrionario adyacente a él. En esta etapa (en las paredes anticlinales del endotegmen del opérculo) son visibles los cuerpos hemisféricos de cutina. A los 36-38 dda el embrión tiene forma de cono, su cotiledón es mucho más grande que el eje y el suspensor. A los 78 dda el embrión representa el 1\% o menos del volumen total de la semilla madura, contiene numerosos granos de almidón, y reacciona positivamente a lípidos y proteínas. En su eje se distinguen la caliptra y el meristemo apical del brote, rodeado por la vaina del cotiledón; aún puede haber vestigios del suspensor.

\section{Discusión}

La protección de la semilla madura de T. pavonia se ubica en la exotesta, el exotegmen, el endotegmen y el endospermo. En la cubierta seminal abundan los taninos tanto en lúmenes como en paredes. Al respecto, Mohamed-Yasseen et al. (1994) señalan que la dureza de las cubiertas y la presencia de compuestos fenólicos protegen contra daños mecánicos y ataque de patógenos y que a su vez contribuyen a la conservación de la viabilidad de la semilla. Nosotros encontramos que en las semillas secas o imbibidas de $T$. pavonia proliferan hifas de hongos en el polo calazal y por la zona hilo-micropilar, por lo que aparentemente los taninos presentes no constituyen una defensa suficiente y eficaz. Por otro lado, tal parece que los hongos no interfieren en el desarrollo y la germinación de las semillas.

Lenz (1956), Rudall et al. (1984) y Manning y Goldblatt (1991) señalan la presencia de cuerpos refringentes inicialmente sin color y luego obscuros en algunos de los estratos de las cubiertas seminales de Iris, Crocus y en Nivenia, Klatia y Witsenia, respectivamente. Depósitos de esta índole en la cubierta seminal de T. pavonia, nosotros los interpretamos como taninos. Manning y Goldblatt (1991) proponen que estos depósitos obscuros en las cubiertas de las semillas de Iridaceae pueden considerarse como un carácter primitivo, de acuerdo a sus resultados de un análisis cladístico. Estos mismos autores señalan que posiblemente tales depósitos obscuros también sean responsables de las coloraciones rojas a castañas que presentan la mayoría de las semillas de Iridaceae.

Netolitzky (1926) consigna la presencia de aceite en la endotesta y Huber (1969, citado por Manning y Goldblatt,
1991) señala que la presencia de lípidos en la mesotesta de las semillas de Iridaceae es una característica que las distingue como familia; por otro lado Lenz (1956), Rudall et al. (1984), Chichiriccó (1986) y Manning y Goldblatt (1991) no usaron métodos para detectar lípidos y pasaron por alto este carácter de posible valor taxonómico en la familia. En este trabajo nosotros encontramos gran cantidad de lípidos en la mesotesta de la semilla de T. pavonia.

Manning y Goldblatt (1991) encontraron que en las Nivenioideae leñosas estudiadas, las características de desarrollo y estructura de la cubierta seminal son importantes para entender las relaciones filogenéticas de este grupo. Molseed (1970) opina que aunque la anatomía de las cubiertas seminales parece variar dentro del género Tigridia, las características de la superficie de la semilla parecen tener poco valor taxonómico. En opinión de Goldblatt (1990), la tribu Tigrideae está poco entendida taxonómicamente. Nosotros pensamos que una investigación sobre la embriología de diversos géneros y especies de Tigrideae podría aportar datos muy valiosos para apoyar su taxonomía.

Es posible que el cambio en la forma del saco embrionario (de muy estrecho y alargado a piriforme), parcialmente ocasionado por el considerable aumento en el tamaño de algunas células del exotegmen, esté relacionado con reservar espacio para el ulterior desarrollo del endospermo y del embrión en la semilla, ya que esto ocurre a los 21-28 dda, y a partir de los 36-38 dda la semilla ya no experimenta cambios notorios en su tamaño.

Nosotros caracterizamos como hipostasa en T. pavonia, una región de la nucela en donde inicialmente algunas células contienen pequeños cuerpos de taninos castaños junto a las paredes, y posteriormente los lúmenes se llenan con taninos compactos. También sus paredes se engruesan, tanifican y lignifican. La posición del cojín de hipostasa en la base de la nucela y junto al tejido vascular, y las características de sus células arriba mencionadas, nos permiten apoyar la hipótesis de que su función sea de protección de esta región de interrupción de la cutícula nucelar.

Hay una zona proximal a la hipostasa con células parenquimáticas que almacenan lípidos abundantes, a la cual nosotros llamamos abultamiento calazal. Netolitzky (1926) observó en Iris un abultamiento de la cálaza al cual llamó "eleosoma" quizás porque también encontró que sus células almacenan lípidos. Es posible que este "eleosoma" de Iris corresponda al abultamiento calazal de T. pavonia. En general, se considera que las estructuras externas con células parenquimáticas ricas en triglicéridos son una recompensa para los posibles dispersores. Nosotros no sabemos si existe algún o algunos dispersores de las semillas de T. pavonia. Molseed (1970) señala que no se ha descubierto algún vector de dispersión para el género completo, excepto el movimiento de las cápsulas.

En las semillas semimaduras de T. pavonia (21-36 dda), los dos primeros estratos de la mesotesta contienen 
cloroplastos que posteriormente pierden la clorofila y forman granos de almidón en la semilla madura. Bain y Mercer (1966) encontraron que en semillas de Pisum sativum los amiloplastos pueden formarse a partir de cloroplastos maduros por medio de una síntesis extensiva de almidón, igual que como ocurre cuando se forman a partir de proplastidios. En este estudio no fue posible dilucidar la naturaleza de las estructuras elipsoidales con reacción positiva a azul-negro de naftol, para proteínas contenidas en las células del abultamiento calazal. Por su apariencia, y de acuerdo con Bewley y Black (1978), pudiera tratarse de vacuolas que almacenan proteínas, por lo que sería interesante su estudio con técnicas de microscopía electrónica.

Las paredes engrosadas y tanificadas, así como los abundantes y diversos taninos que ocupan los lúmenes de las células del endóstomo y el exóstomo, pueden interpretarse como una defensa para evitar daños mecánicos y entrada de patógenos a través de estas aberturas naturales. El espacio que queda entre el exóstomo y el endóstomo podría relacionarse con la entrada de agua y de aire necesarios para la germinación.

Bhojwani y Bhatnagar (1974) opinan que los opérculos en general se forman por la proliferación del tegumento interno en su ápice. De acuerdo con las ideas de Scott (1964), quizás en la formación de las capas cuticulares del endotegmen del opérculo de T. pavonia intervenga el estímulo de las heridas ocasionadas por la intensa expansión que experimentan sus células. Es posible que los cuerpos globulares y cilíndricos de cutina, encontrados en el endotegmen del opérculo de T. pavonia, se formen por una cutinización excesiva. Fritz (1937, Planta 26: 693-704; citado por Martin y Juniper, 1970) menciona que la cutinización excesiva puede involucrar la formación de cistolitos cuticulares y de abultamientos en la lámina media. El depósito de cutina en forma de pequeñas gotitas ya ha sido observado en otras especies y órganos (Esau, 1976; Martin y Juniper, 1970); quizás esto explique el aspecto que muestran los cuerpos de cutina del endotegmen del opérculo de T. pavonia. Se han atribuido diversas funciones al opérculo; la más generalizada es que facilita la germinación de la semilla. Sin embargo, se considera que es una estructura poco entendida y estudiada, cuyo origen en las angiospermas es polifilético (Boesewinkel y Bouman, 1984). En el opérculo de T. pavonia, nosotros pensamos que los cuerpos de cutina y el abundante depósito de taninos en las células del endotegmen hacen que la zona micropilar esté más protegida que otras partes de la semilla. Así, el opérculo funciona no sólo para facilitar la germinación, sino también para proteger la semilla intacta (Boesewinkel y Bouman, 1984). La presencia de capas cuticulares concéntricas muy espesas hacen que el opérculo maduro tenga mayor rigidez y resistencia que la cubierta seminal circundante, lo que a su vez podría coadyuvar a que la ruptura de las paredes periféricas del opérculo ocurra por una diferente resistencia de las paredes celulares, al aumentar la presión por la imbibición del endospermo y del embrión. La formación de cutículas en las semillas es un fenómeno poco estudiado (Martin y Juniper, 1970), lo mismo que las funciones y características del opérculo de la semilla (Boesewinkel y Bouman, 1984). Hasta donde sabemos no se ha informado la presencia de opérculo dentro de ningún otro miembro de Iridaceae, ni tampoco de la presencia de espesamientos de cutina para semillas de angiospermas en general. Por lo anterior, creemos que una investigación a nivel molecular y ultraestructural sobre la ontogenia de estas estructuras podría aportar datos interesantes para su mejor entendimiento.

La presencia de paredes de transferencia notorias en las células de la base del cigoto y luego del suspensor, y en la pared del saco embrionario de las zonas micropilar y calazal de $T$. pavonia nos permiten suponer que son regiones de transporte intenso de nutrientes hacia el saco embrionario. Johansson y Walles (1993) observaron paredes de transferencia en estas mismas regiones en semillas de Vicia faba. Chamberlin et al. (1993) encontraron en Glycine max una mayor acumulación de granos de almidón en los polos calazal y micropilar desde la etapa de cigoto hasta la de embrión globular. Nosotros observamos algo semejante en la semilla de T. pavonia a los 11 dda. Es posible que las células del gorro de la nucela también contribuyan en la alimentación inicial del cigoto y el joven embrión. Los cambios que ocurren en las células de la nucela del polo calazal y la presencia de paredes de transferencia, primero en la pared del saco embrionario y después en el endospermo celular cercano a la nucela, nos hacen suponer que sea una región de intenso tráfico de sustancias nutritivas de la nucela hacia el saco embrionario en crecimiento, y después hacia el embrión y endospermo, por lo que quizás esta zona del endospermo funcione como un haustorio semejante al de Romulea rosea var. reflexa (Steyn, 1973). Las características del endospermo nuclear y su celularización coinciden con un informe para Iris munzii (Lenz, 1956), ya que las paredes del endospermo de $T$. pavonia empiezan a engrosar en una área de la zona central de la semilla hacia la cálaza. Molseed (1970) anota que la punta del cotiledón de Tigridia tiene función haustorial. Por la manera en que el cotiledón se ensancha durante la germinación, aparentemente toda su superficie actúa como haustorio. No es común la presencia de taninos en las células del endospermo. La presencia de estos compuestos detectada por nosotros mediante pruebas histoquímicas requiere de su corroboración mediante análisis químicos.

\section{Agradecimientos.}

Al CONACYT, registro 118732 y al Programa Nacional de Etnobotánica de la Universidad Autónoma Chapingo, registro 110301, por el apoyo económico brindado. Al Sr. Miguel Vega Zúñiga por su apoyo en la microtecnia y el trabajo 
fotográfico. A la Unidad de Microscopía Electrónica del C. P. por las micrografías de barrido. Al Ing. Agr. Heriberto Torres Navarro y vecinos de San Miguel Tlaixpan, Texcoco, Edo. de México, por su ayuda en la localización y préstamo del predio donde se recolectó el material botánico.

\section{Literatura citada}

Bain J.M. y Mercer F.V. 1966. Subcellular organization of the developing cotyledons of Pisum sativum L. Australian Journal of Biological Sciences 19:49-67.

Bewley J.D. y Black M. 1978. Physiology and Biochemistry of Seeds in relation to Germination. I. Development, Germination and Growth. Springer-Verlag. Berlín.

Bhojwani S.S. y Bhatnagar S.P. 1974. The Embryology of Angiosperms. 3a. ed. Vikas Publishing House. Nueva Delhi.

Boesewinkel F.D. y Bouman F. 1984. The seed: structure. En: Johri E.M. Ed. Embryology of Angiosperms. Springer-Verlag, Nueva York, 567-610.

Chichiriccó G. 1989. Embryology of Crocus thomasii (Iridaceae). Plant Systematics and Evolution 168:39-47.

Chamberlin M.A., Horner H.T. y Palmer R.G. 1993. Nutrition of ovule, embryo sac, and young embryo in soybean: an anatomical and autoradiographic study. Canadian Journal of Botany 71:1153-1168.

Danilova M.F., Nemirovich-Danchenko E.N., Komar G.A. y Lodkina M.M. 1995. The seed structure of monocotyledons. En: Rudall P.J., Cribb P.J., Cutler D.F. y Humphries C.J. Eds. Monocotyledons: Systematics and Evolution. Royal Botanic Gardens, Kew, 272-461.

Esau K. 1976. Anatomía Vegetal. Omega. Barcelona.

Fisher D.B. 1968. Protein staining of ribboned Epon sections for light microscopy. Histochemie 16:92-96.

Gardner R.O. 1975. Vanillin hydrochloric acid as histochemical test for tannin. Stain Technology 50:315-318.

Goldblatt P. 1990. Phylogeny and classification of Iridaceae. Annals of the Missouri Botanical Garden 77:607-627.
Johansen D.A. 1940. Plant Microtechnique. McGraw-Hill. Nueva York.

Johansson M. y Walles B. 1993. Functional anatomy of the ovule in broad bean, Vicia faba L. II. Ultrastructural development up to early embryogenesis. International Journal of Plant Science 154:535-549.

Lenz L.W. 1956. Development of the embryo sac, endosperm and embryo in Iris munzii and the hybrid I. munzii X I. sibirica "Caesar's Brother". Aliso 3:329-343.

Manning J.C. y Goldblatt P. 1991. Systematic and phylogenetic significance of the seed coat in the shrubby African Iridaceae, Nivenia, Klatia, and Witsenia. Botanical Journal of the Linnean Society 107:387-404.

Martin J.T. y Juniper B.E. 1970. The Cuticles of Plants. Edward Arnold. Edinburgo.

Martínez M. 1967. Las Plantas Medicinales de México. 6a ed. Botas. México, D.F.

Mohamed-Yasseen Y., Barringer S.A., Splittstoesser W.E. y Costanza S. 1994. The role of seed coats in seed viability. The Botanical Review 60:426-439.

Molseed E.W. 1970. The Genus Tigridia (Iridaceae) of Mexico and Central America. University of California Publications in Botany 54:1-127.

Netolitzky F. 1926. Anatomie der Angiospermen-Samen. Handbuch der Pflanzenanatomie. Band X. Borntraeger. Berlín.

Rudall P., Owens S.J. y Kenton A.Y. 1984. Embryology and breeding systems in Crocus (Iridaceae), a study in causes of chromosome variation. Plant Systematics and Evolution 148:119-134.

Sass J.E. 1958. Botanical Microtechnique. 3a ed. Iowa State University Press. Ames, Iowa.

Scott F.M. 1964. Lipid deposition in intercellular space. Nature 203:164-165.

Steyn E. 1973. 'N Embriologiese ondersoek van Romulea rosea Eckl. var. reflexa Beg. 2. Die ontwikkeling van die endosperm, embrio saadhuid. Journal of South African Botany 39:235-243. 